\title{
Using systems approaches to design and evaluate ideotypes for specific environments
}

\author{
M.J. KROPFF $F^{1,2,3 *}$, A.J. HAVERKORT ${ }^{2}$, P.K. AGGARWAL ${ }^{1}$ and \\ P.L. KOOMAN ${ }^{2 ; 3}$ \\ ${ }^{1}$ The International Rice Research Institute, P.O. Box 933, 1099 Manila, Philippines; \\ ${ }^{2}$ DLO-Research Institute for Agrobiology and Soil Fertility (AB-DLO), P.O. Box 14,6700 AA \\ Wageningen, The Netherlands; ${ }^{3}$ Department of Theoretical Production Ecology, Wageningen \\ Agricultural University, P.O. Box 430,6700 AK Wageningen, The Netherlands
}

Key words: breeding, $G \times E$, ideotype, crop model, plant type design, rice

\begin{abstract}
An eco-regional approach is needed to find ways to increase agricultural production to meet the growing demand for food in large parts of the world, while sustaining the environment. The selection of germplasm is a key element in such an approach. Selection of varieties for particular environments is mostly based on the intuition of the breeder. With the increasing knowledge of processes that determine crop production and the availability of systems approaches, the opportunity emerged to design crop ideotypes and improve the efficiency of germplasm evaluation programs.

A systems framework to target plant types for different production environments is presented. Specific examples are given of on-going research to design and evaluate the suitability plant types for different environments for major crops such as rice and potato.
\end{abstract}

\section{Introduction}

The objective of any breeding program is the development of improved breeding lines/varieties for a specific product with a defined quality for target environments. For most crops this breeding process involves a time investment of 10-15 years (Hunt 1993), although the process is shorter for tropical crops like rice, where several crop cycles can be completed within a year. Some kind of conceptual design has been used since the onset of breeding activities through the identification of parents with complementary traits which combined were expected to improve existing cultivars. Donald (1962) identified the importance of basic knowledge on the processes driving the production of dry matter, and economic yield formation. This led to a design driven breeding approach (Donald 1968). He argued that the chance of finding a strongly improved plant type in conventional breeding without a clear design would be small. In a recent review, however, Hunt (1993) concluded that only a few breeding programs have adopted the concept of a formal ideotype design as a major breeding activity.

- Present address: 2 and 3 
An example of an improved plant type design that had a major impact on agricultural production is the short stature design for cereals that was developed in the 1960s. The introduction of semi-dwarf varieties like the rice variety IR 8 was successful because fertilizers came available at that time to which semi-dwarf varieties responded much better than traditional varieties. This resulted in the so-called green revolution which resulted in a tripling of rice yields in Asia (IRRI 1993). The yield increases were obtained by a new plant type and an adjustment of the agronomic environment (fertilizers, irrigation and pesticides) to optimize genotype $\times$ environment interactions. This can be characterized as a seed based technology with a focus on wide adaptation.

Although the wide adaptation concept worked for some systems like the homogeneous irrigated rice systems in the tropics and subtropics and wheat in South Asia, it has been recognized that strong genotype $\times$ environment $x$ management interactions in most agricultural systems make it necessary to use genotypes that are adapted to the specific agro-environments. Besides that, the issue of designing ideotypes has to be seen in the context of required developments of the agricultural production systems in the future. There is an increasing awareness that food production must strongly be increased in the coming decades to meet the demand created by growing populations (IRRI 1989). This production increase has to be achieved, on less land, with less labor, less water, and less pesticides and they must be sustainable through conserving scarce natural resources. To meet the challenges to increase food production, ways have to be found to improve the productivity and profitability of agricultural production systems. That can only be done by using a systems approach that helps to optimize local agricultural production systems. That will involve improved crop management systems, but also new crop types. For rice, for example, new varieties with a higher yield potential will be needed early in the next century because yields will quickly reach the potential yield of current varieties (Penning de Vries 1993).

Crop ideotype designs should then be based on sound physiological understanding of the system and its interaction with edaphic, climatic, biotic and management factors. Such an understanding should facilitate the prediction of the effects of different combinations of physiological/morphological traits in different environments. With the advancement of ecophysiological systems modelling of crops in the past decades, the potential to integrate physiological/morphological process level knowledge to design new plant types has emerged. Several examples of such an approach were presented at the international symposium on systems approaches in agricultural development in 1991 (Penning de Vries et al. 1993).

This paper reviews the opportunities of using systems approaches to design plant types targeted for specific environments. First a systems framework for targeting plant types for different production environments is discussed. Then an approach is presented to design ideotypes for potential yields, resource 
limited yields and yields expected under yield reducing (pests) conditions, followed by suggestions for a more efficient breeding program in which systems approaches are used in the different stages of the breeding process. Specific examples are given for rice and potato.

\section{A systems framework for targeting crop ideotypes designs to different environments}

To understand the differences in the performance of genotypes in the wide ranges of environments in which crops are grown, it is necessary to use a systems framework in which the role of the different factors that determine yield are distinguished. First it has to be recognized that single plants grow differently from plants grown in a crop situation at a specific density (Kropff et al. 1994a). Because one is only interested in crop production per unit of cropped area and not per plant, it would be better to use the term crop ideotype instead of plant ideotype.

A simple widely used generic model for crop growth and production can be used as a framework for designing crop ideotypes. The yield of a crop $\left(Y, \mathrm{~g} \mathrm{~m}^{-2}\right)$ is determined by the amount of photosynthetically active solar radiation it intercepts $\left(R_{i}, \mathrm{~J} \mathrm{~m}^{-2}\right)$, its conversion efficiency into dry matter $\left(E, \mathrm{~g} \mathrm{~J}^{-1}\right)$, and the proportion of total dry matter in the harvested parts $\left(H_{i},-\right)$ and its dry matter content $\left(D_{m c}\right)$ :

$$
Y=R_{i} E H_{i} / D_{m c} \text {. }
$$

The value of each parameter in this simple model of crop growth is determined by a number of underlying processes. $R_{i}$ depends on the time course of the leaf area index and light interception characteristics of the canopy, $E$ depends on photosynthesis and respiration rates, $H_{i}$ depends on dry matter partitioning processes and the dry matter content (for potato) depends on the soil moisture content and the temperature during growth.

Several production situations have to be distinguished in which different environmental factors determine the parameter values in the simple model. In the potential production situation, where water and nutrients are available in ample supply and the crop is free of pests and weeds, only the growth determining factors radiation, temperature and crop physiological characteristics play a role. Plant processes that govern potential yield are related to light interception, light use efficiency, growth duration and dry matter distribution. Potential yields may vary considerably across environments. For example, the potential yield of rice varies between $6 \mathrm{tha}^{-1}$ in the tropical wet season to $15 \mathrm{tha}^{-1}$ in temperate environments (Kropff et al. 1994d). Crop ideotypes for increasing potential yields have to focus on those physiological traits that increase the light interception during the season, the efficiency of light use or the harvest index. 


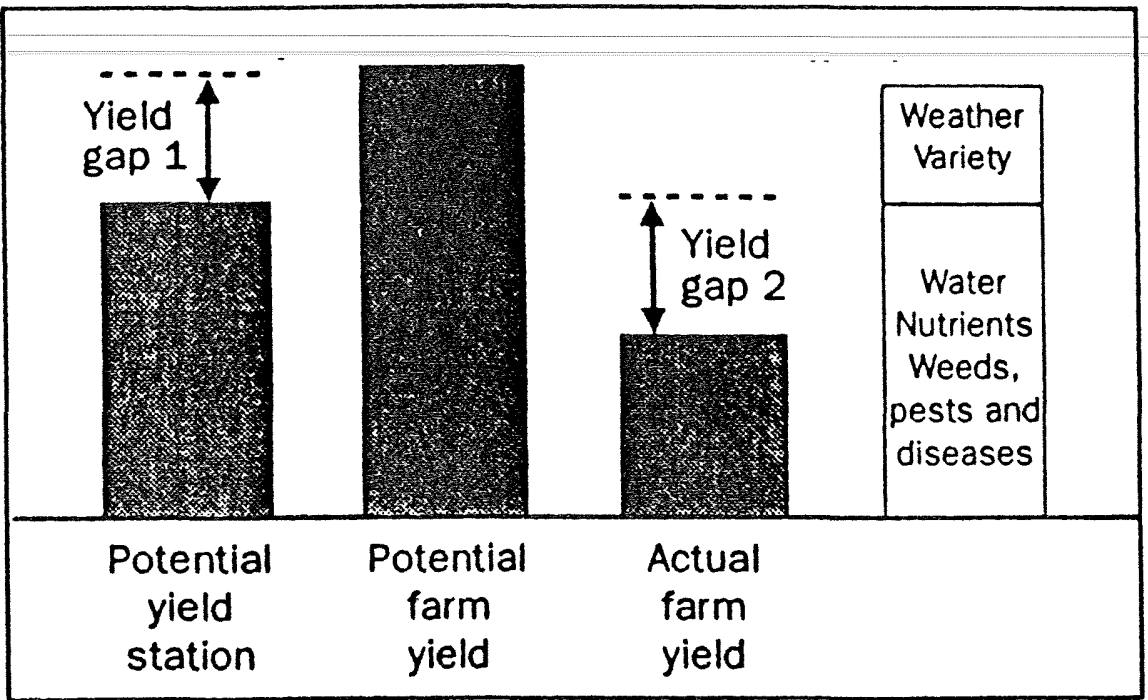

Fig. 1. Schematic presentation of the different yield gaps: yield gap 1 indicates the difference in potential yield between environments (or between station and a site) which is the result of differences in radiation and temperature regime after sowing and the varietal characteristics. The second yield gap indicates the difference between the potential yield in a given environment and the actual yield. This yield gap can be split in several components.

In most production situations, actual yields are much lower than potential yields because of insufficient availability of growth limiting resources to the crop (water and/or nutrients, mainly nitrogen) and growth reduction by insects, diseases and weeds. In these situations, the system is much more complex. In addition to the processes involved in the potential production situation, processes related to the efficiency of water uptake and water-use efficiency, the efficiency of uptake of nutrients and the nutrient-use efficiency in the different physiological processes and crop-pest interactions may affect the $R_{i}$ (through leaf canopy development) or $E$. In these production situations, yields range from yield levels close to the potential yield to extremely low yields in heavily exploited areas where no fertilizers are used like in many of the upland rice ecosystems. Ecophysiological models for the effect of water stress and nitrogen limited yields have been developed for several crops with varying results (e.g. Penning de Vries et al. 1993).

Because of the different processes that are involved in the production situations, new crop type designs have to be developed for a specific production situation. That should be based on thorough understanding of the factors that are responsible for the so-called yield gap between actual and potential yields in that particular environment. The way in which yield gaps are defined in the framework that is used here is illustrated in figure 1. In situations where there is a considerable yield gap, it might be more efficient to first identify the major constraints and management strategies to improve the resource-use efficiency for the limiting factors or to reduce pest effects before designing new crop ideotypes, so that the breeding effort, which is a 
long term investment, can be focused on the major problems that cannot be solved by improved management.

\section{Designing improved crop types using systems approaches}

\section{Increasing potential yields}

The potential yield of a crop is defined only by varietal characteristics and the seasonal pattern of the environmental variables temperature, daylength and radiation. The potential yield of a specific cultivar differs among environments, in different years and between seasons in the same year. In a particular environment only cultivar characteristics determine the potential yield.

\section{Rice}

Rice breeding programs of National Research Systems in rice growing countries and the International Rice Research Institute (IRRI) collaborate intensively to develop improved rice varieties for specific environments. Through the international network for the exchange of germplasm, the best varieties from many countries are evaluated in 95 countries in ecosystem oriented nurseries and so-called stress oriented nurseries. In this program there is a need for systems approaches to target genotypes to specific environments and to reduce the number of sites and years for evaluation. The timing of phenological events is important in rainfed lowland systems to ensure flowering occurs well before the end of the rainy season, and in temperate environments, where the total crop duration has to match the length of the growing season as determined by the annual temperature cycle. Work has been initiated recently to model phenological events to help targeting varieties to those specific environments.

However, most rice is grown in tropical and subtropical environments, where the duration has to be minimized without sacrificing potential yield to allow the cultivation of several crops per year. Since the 1960 s breeders were successful in this aspect: varieties have been released with a similar potential yield as IR8 despite differences in growth duration (IR72 has a growth duration of about 110 days vs. 125 days for IR8) (Kropff et al. 1993ab; Cassman et al. 1993). Therefore, the key issue for rice is to increase the yield potential in rice with a minimum increase in the total duration in tropical environments.

IRRI scientists proposed modifications to the present high-yielding crop types that would enhance the potential yield for rice in irrigated direct-seeded conditions considerably (IRRI 1989). The proposed characteristics for the designed new crop type came from different perspectives, mainly based on physiological analyses and include: a reduced tillering capacity, no unproductive tillers, over 200 grains per panicle, sturdy stems, harvest index of 0.6 , 
13-15 $\mathrm{t} \mathrm{ha}^{-1}$ yield potential in the tropical dry season: Breeding activities started in 1989 with the identification of donors for the various traits, most of which were so-called javanicas from Indonesia (Peng et al. 1994).

The physiological characteristics needed to support greater yield potential were evaluated in more detail using models at different level of complexity (Penning de Vries 1991; Dingkuhn et al. 1991; Kropff et al. 1994ab). In a simple model analysis, Kropff et al. (1994a) concluded that rice yields beyond $10 \mathrm{tha}^{-1}$ in the tropics should either result from (i) increased accumulation and allocation of stem reserves, (ii) from a prolonged grain filling period $\left(R_{i}\right)$, or (iii) from an increased growth rate $(E)$ during grain filling. They argued that an increase of stem reserves allocation from 2 to $2.5 \mathrm{tdry}$ matter ha-1 would be the maximum without prolonging the vegetative period. Such a prolongation is not agronomically desirable. Besides that, a sturdy stem and a high LAI (leaf area index) are needed to support a larger grain yield. For a grain yield of $15 \mathrm{t} \mathrm{ha}^{-1}$ at $14 \%$ moisture content, 40 days of effective grain filling would be needed at the same growth rate as the current varieties during 25 days (Penning de Vries 1991; Kropff et al. 1994a,b). Thus, a higher yield potential requires a longer duration, unless the vegetative phase is shortened. Therefore it is needed to determine how much the vegetative phase can be shortened without losing yield potential.

To achieve such yields, an increased sink size is also required. A yield of $15 \mathrm{tha}^{-1}$ requires 60,000 spikelets $\mathrm{m}^{-2}$, which is $13 \%$ greater than the total number of filled plus unfilled spikelets produced by a recently tested hybrid, and 33\% greater than for the inbred variety IR72 (Kropff et al. 1994b). Thus the fundamental parameters are: increased sink size (i.e. spikelets $\mathrm{m}^{-2}$ ), a longer period of effective grain filling, and a longer duration of green leaf area and active canopy photosynthesis to match the increase in grain fill duration. These parameters are similar for an increased yield potential in any rice growing environment.

In a more detailed analysis, we used the ecophysiological model ORYZA1, which was developed and evaluated using the data sets from field experiments conducted in 1991-1993 at the IRRI experimental farm which were designed to restore the yield potential in rice (Kropff et al. 1994c). This model is based on the Wageningen models SUCROS (Spitters et al. 1989) and MACROS (Penning de Vries et al. 1989). The model simulates growth of a rice crop on basis of the light distribution within the canopy, single leaf photosynthesis as a function of leaf $\mathrm{N}$ concentration and light intensity and respiration. The accumulated dry matter is partitioned among the various plant organs, which is a function of phenological development. The model simulates leaf area index development and accounts for sink limitation.

Total potential above-ground biomass (ranging from 11.5-17.8 $\mathrm{t} \mathrm{ha}^{-1}$ in wet and dry seasons, respectively) as well as panicle dry matter (ranging from 5.7-9.8 $\mathrm{t} \mathrm{ha}^{-1}$ ) was simulated accurately by the model (table 1). The parameters used in these simulations were derived from the highest yielding 
Table 1. Observed and simulated crop characteristics for field experiments on yield potential in rice in different environments (standard error between brackets). (Source: Kropff et al. 1994c)

\begin{tabular}{|c|c|c|c|c|}
\hline & IRRI WS & Japan & IRRI DS & Yanco \\
\hline Year & 1991 & 1987 & 1992 & 1992 \\
\hline Variety & IR72 & Nipponbare & IR72 & YRL39 \\
\hline Biomass obs. $\left(\mathrm{t} \mathrm{ha}^{-1}\right)$ & $11.5(0.6)$ & $12.8(0.5)$ & $17.8(0.6)$ & $28.9(1.1)$ \\
\hline Biomass sim. $\left(\mathrm{tha}^{-1}\right)$ & 11.5 & 13.2 & 15.4 & 27.3 \\
\hline Yield obs. ( $t$ ha ${ }^{-1}$, panicle dry wt) & $5.7(0.2)$ & $7.8(0.5)$ & $9.8(0.2)$ & $14.7(0.6)$ \\
\hline Yield sim. $\left(t_{\text {ha }}{ }^{-1}\right.$, panicle dry wt) & 7.26 & 7.41 & 9.49 & 14.3 \\
\hline Maximum LAI obs. $\left(\mathrm{m}^{2} \mathrm{~m}^{-2}\right)$ & $4.3(0.4)$ & $5.3(0.7)$ & $6.0(0.5)$ & $14.0(1.0)$ \\
\hline Maximum LAI sim. $\left(\mathrm{m}^{2} \mathrm{~m}^{-2}\right)$ & 4.9 & 8.9 & 6.4 & 12.8 \\
\hline Crop duration (d) & 109 & 153 & 110 & 159 \\
\hline Grain filling duration sim. (d) & 29 & 32 & 30 & 39 \\
\hline \multicolumn{5}{|l|}{ Mean temperature } \\
\hline sowing-flowering (-C) & 28.1 & 23.3 & 26.0 & 21.3 \\
\hline flowering-maturity (-C) & 27.7 & 25.6 & 27.9 & 22.9 \\
\hline \multicolumn{5}{|l|}{ Av. daily incoming radiation } \\
\hline sowing-flowering $\left(\mathrm{MJ} \mathrm{m}^{-2}\right)$ & 15.2 & 16.3 & 17.4 & 22.9 \\
\hline flowering-maturity & 18.9 & 13.5 & 21.9 & 22.6 \\
\hline \multicolumn{5}{|l|}{ Absorbed total radiation } \\
\hline sowing-flowering $\left(\mathrm{MJ} \mathrm{m}^{-2}\right)$ & 189 & 195 & 278 & 413 \\
\hline flowering-maturity & 215 & 301 & 371 & 1747 \\
\hline Light use efficiency $\left(\mathrm{g} \mathrm{MJ}^{-1}\right)$ & 2.8 & 2.6 & 2.7 & 2.5 \\
\hline
\end{tabular}

dry season experiment at IRRI (development rates, partitioning coefficients, leaf-N content, relative growth rate of the leaf area). The ORYZA1 model was also used to predict yield potential for a temperate environment. In Yanco Australia, yields of close to $15 \mathrm{t} \mathrm{ha}^{-1}$ have been observed (Williams and Lewin, personal communication). Model predictions for these independent data were very close to that level (table 1). Model analysis showed that the differences in yield potential between for example the IRRI wet season $\left(6 \mathrm{tha}^{-1}\right)$ and Yanco $\left(15 \mathrm{tha}^{-1}\right)$ were the result of a low temperature in Yanco causing a long duration of grain filling and a high radiation level in Yanco which increased the $R_{i}$.

These simulations confirm that a genotype with a $15 \mathrm{tha}^{-1}$ yield potential in the tropics must have a grain filling duration in tropical environments that is comparable to that of current varieties grown at higher latitudes where temperatures are cooler as in Yanco. For several crop species, increased 'stay green' (i.e. longer green leaf duration during grain filling) indeed has been a major achievement of breeders and agronomists in the past decades (Evans 
1990). New physiological insight is needed in the grain filling process to understand why the grain filling process stops in current varieties, while there are many unfilled spikelets as observed in several experiments (Kropff $e t$ al. 1994b). It was concluded that the proposed characteristics of the IRRI new plant type (Peng et al. 1994), such as more spikelets per panicle and a larger flag leaf will not by definition lead to the required longer grain filling duration with a sustained high growth rate of the crop. Currently, prototypes of the new crop type is being evaluated by IRRI and many of the desired characteristics, like a large thick flag leaf, more spikelets $\mathrm{m}^{-2}$ and less tillers per plant, have successfully been introduced in the lines, although higher yields have not been observed yet (Peng et al. 1994).

To analyse the need for different crop types for different environments, Aggarwal et al. (1995) determined the importance of various traits for the dry season and the wet season using ORYZA1. Crop characteristics of IR72 (Kropff et al. 1994) and weather data of Los Banos for 1992 were used. The critical model parameter values were varied between $+50 \%$ and $-50 \%$ with respect to those of IR72 to simulate the effect of a change in leaf area development, sink size, leaf $\mathrm{N}$ distribution in the canopy, light extinction coefficient during vegetative and reproductive development stages, leaf $\mathrm{N}$ content, maintenance respiration of leaves, fraction of stem reserves, dry matter partitioning, and crop development rates during juvenile phase and grain filling period. It was assumed that $50 \%$ change in model inputs will represent the extremes of variation available for most crop parameters. The results indicated that the relative importance of different traits may change with season and a 50\% change in individual traits can provide a maximum of $19 \%$ increase in yield potential. The magnitude of response to input change may however be dependent on cropping year, location and level of management.

To further examine the opportunities for increasing rice yields substantially in different seasons, an additional analysis was done by using 'hypothetical' plant types with different combinations of traits. These crop types simulated various combinations of source capacity, sink size and grain filling duration (table 2) (Aggarwal et al. 1995). The probability distributions of yield for the Los Banos, Philippines situation are presented in figure 2. Increased source availability (crop type 1) always increased yield. Average increase was between 1.0 and $1.4 \mathrm{tha}^{-1}$ irrespective of the season. Increase in grain filling duration alone (crop type 2 ) resulted in increased grain yield, the magnitude of increase in yield relative to the control was less in the dry season than in the wet season. In $50 \%$ of the years, increase in the wet season was more than $0.8 \mathrm{tha}^{-1}$. In the dry season, the increase was between 0 and $0.6 \mathrm{t} \mathrm{ha}^{-1}$ only. In many seasons, grain weight had already reached its maximum permissible value and thus there was a sink limitation.

Increase in spikelet number (crop type 3 ) resulted in hardly any change in yield in the dry season and in the wet season. When the number of spikelets increased simultaneously with LAI and leaf N content (crop type 4), 50\% 

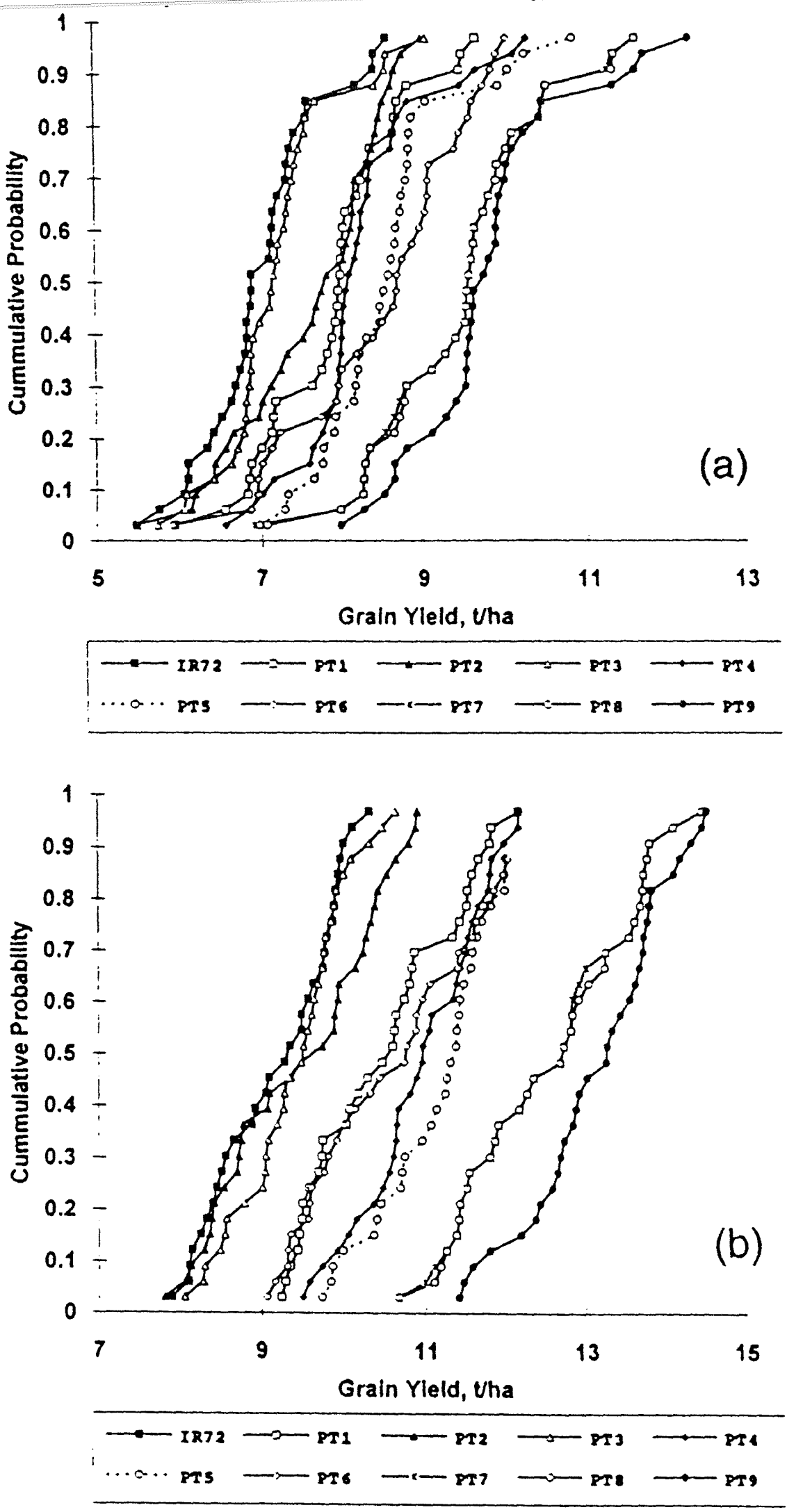

Fig. 2. Simulated grain yield probabilities of various plant types (see table 2) in Los Banos, Philippines, for the dry season (A) and the wet season (B), 1992. 
Table 2. Characteristics of 9 hypothetical crop types in comparison to the check variety IR72. Traits: SLA (specific leaf area); NFLV (leaf N content); SPGF (spikelet formation factor), WGRMX (maximum 1000 grain weight) and DVRR (development rate during grain filling).

\begin{tabular}{lrrrrr}
\hline Crop type & \multicolumn{5}{c}{ Percent change in input parameter } \\
\cline { 2 - 6 } & SLA & NFLV & SPGF & WGRMX & DVRR \\
\hline IR 72 & 0 & 0 & 0 & 0 & 0 \\
1 & +20 & +20 & 0 & 0 & 0 \\
2 & 0 & 0 & 0 & 0 & -20 \\
3 & 0 & 0 & +20 & 0 & 0 \\
4 & $\cdots+.+20$ & +20 & +20 & 0 & 0 \\
5 & 0 & 0 & +20 & +20 & -20 \\
6 & +20 & +20 & 0 & 0 & -20 \\
7 & +20 & +20 & +20 & 0 & -20 \\
8 & +20 & +20 & 0 & +20 & -20 \\
9 & +20 & +20 & +20 & +20 & -20 \\
\hline
\end{tabular}

yields exceeded $10.9 \mathrm{t} \mathrm{ha}^{-1}$ in the dry season and $8.1 \mathrm{t} \mathrm{ha}^{-1}$ in the wet season. Increased sink capacity due to more spikelets and higher 1000 grain weight together with longer grain filling duration (crop type 5) resulted in substantial yield increases in both seasons. However, only crop types 7,8 and 9 in which the source, sink and grainfilling duration are increased, substantial yield gains of $4 \mathrm{tha}^{-1}$ were simulated.

\section{Potato}

Breeding programmes, of centres such as the International Potato Centre (CIP), but also of private companies in Canada, France and The Netherlands focus on the breeding of potatoes for specific environmental conditions. The most important aspect is to match the growth cycle of the cultivar to the length of the growing season as defined by the temperature. Kooman and Haverkort (1995) developed a simple potato simulation model that can be used for that purpose. The 'LINTUL-POTATO' model overcomes the limitations of other models that only perform well for either tropical conditions or temperate conditions (Haverkort 1990; Haverkort and Harris 1987).

The model 'LINTUL-POTATO' simulates potential total dry matter production and yield on basis of the light use efficiency of intercepted light by a potato crop (Kooman and Haverkort 1995). To predict growth and development over areas with widely varying temperature and daylength regimes, the growth cycle is divided into four phases each starting and ending by a characteristic stage of development. For each phase the key processes are different (figure 3). Phase 0 starts at planting and ends at emergence. The main process is the rate of emergence as a function of temperature. Phase 1 is from emergence to tuber initiation. The main process is foliar expansion 

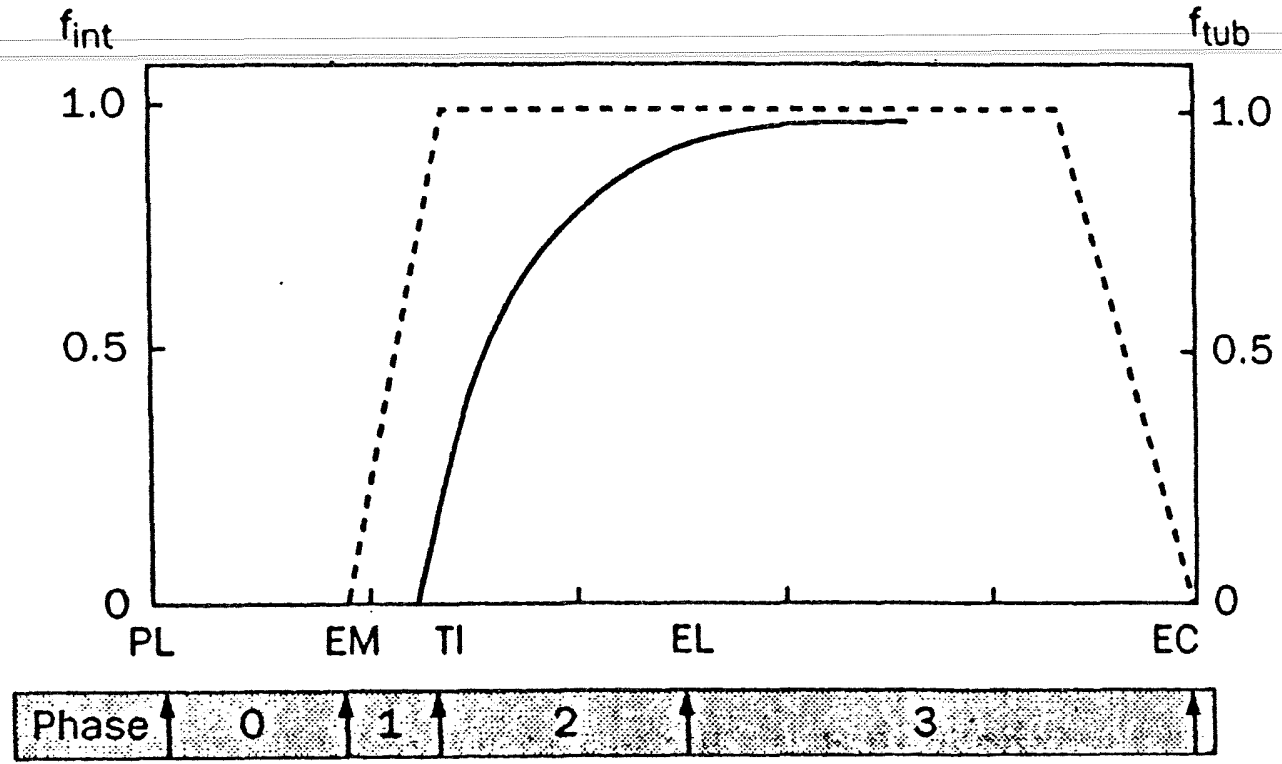

Fig. 3. Schematic representation of the fraction of solar radiation intercepted by the crop ( $F_{\text {int }}$ ) and the fraction of daily produced assimilates partitioned to the tubers $\left(\mathrm{fr}_{\mathrm{tub}}\right)$ from planting (PL) to emergence (EM), the start of tuber growth (TI), the moment that $f_{\text {wab }}$ (EL) reaches the value of 0.9 until the end of crop growth (EC).

which is a function of temperature. After this, leaf expansion is calculated from leaf dry weight increases. Daylength and temperature both determine the duration of this phase and thus the amount of leaves produced. Short days increase the development rate until tuber initiation. Phase 2 is from tuber initiation until the end of leaf growth (defined as the moment when $90 \%$ of the assimilates which are daily produced, are partitioned to the tubers). Temperature determines the duration of this phase. Phase 3 is from the end of leaf growth until the end of crop growth. In Phase 3 all assimilates are partitioned to the tubers. Leaf senescence is a function of temperature.

The model simulated adequately differences between genotypes within the same environment and differences between environments with the same genotype (Kooman, in prep.).

Model analyses showed that the key to the optimization of potential yield in potato is the proper timing of the moment of tuber initiation. If that moment is too late for a particular environment, too much foliar tissue is formed and the tuber growth period can be too short. If tuber initiation is too early, not enough foliar tissue is formed to sustain growth until the end of the growing season. LINTUL-POTATO can be used to determine the cultivar characteristics with respect to temperature and daylength response that give the highest yield in a particular environment. This means that for each environment the optimal moment of tuber initiation can be calculated and only genotypes with such desired earliness have to be evaluated in this environment. 
Nitrogen: a key yield limiting factor

Nitrogen is one of the key nutrients that limit crop growth and production in many prodüction situations. Its main effect is on leaf expansion (and thus $R_{i}$ ), but also the light use efficiency $(E)$ of a crop is affected by $N$. Although there is variability in the $\mathrm{N}$-use efficiency of crops, it appears that optimization of $\mathrm{N}$ management has potentially more impact on yield than breeding for increased $\mathrm{N}$-use efficiency. In farmers fields, the efficiency of $\mathrm{N}$ management may vary considerably as was shown for intensive rice systems in the Philippines (Cassman et al. 1993). Because $\mathrm{N}$ fertilizers are relatively inexpensive, it is not clear if crop type designs have to be developed for $\mathrm{N}$ limited conditions. In the unfavorable environments, where cash flow often does not allow the purchase of inputs, several factors can be limiting and an identification of the most limiting factors has to be conducted first.

The importance of critically evaluating management practices, before starting to develop crop ideotype designs, was illustrated in recent studies at IRRI. A decline in rice productivity had been observed in high yielding intensive rice cropping systems (Flinn et al. 1982, Cassman et al. 1994). On IRRI's experimental farm, rice yielded $10 \mathrm{tha}^{-1}$ in the dry season and $6 \mathrm{tha}^{-1}$ in the wet season in the late sixties with the first semi-dwarf variety IR8, but dry season yields in the 1980s generally did not exceed $6-7 \mathrm{t} \mathrm{ha}^{-1}$ in the dry season and $4-5 \mathrm{tha}^{-1}$ in the wet season at recommended fertilizer rates. It was not known if this was related to genetic factors in recent varieties, because the early semi-dwarf varieties were yielding even lower in recent experiments because of the lack of resistance to diseases. In recent studies where systems analysis and experimentation were combined, yields of about $6 \mathrm{t} \mathrm{ha}^{-1}$ in the wet season and 9-10 $\mathrm{tha}^{-1}$ in the dry season were achieved, indicating that the genetic potential remained the same, despite differences in growth duration (Kropff et al. 1993b; Cassman et al. 1993).

Varieties that strongly differ in duration have different $\mathrm{N}$ requirements. For example, late potato cultivars will build up a higher leaf area index, which requires more $\mathrm{N}$. In the development of crop ideotypes the nitrogen requirements (and other nutrients as well if not abundantly available) have to be identified. For example, a $15 \mathrm{t} \mathrm{ha}^{-1}$ rice crop will require about $300 \mathrm{~kg}$ of $\mathrm{N}$ uptake, whereas a $10 \mathrm{t} \mathrm{ha}^{-1}$ crop only requires $200 \mathrm{~kg} \mathrm{~N}^{-1}$ (Penning de Vries 1991; Kropff et al. 1994a).

\section{Water stress}

Water is one of the most limiting factors for growth and quality of rainfed crops. The effect of water stress on the crop depends on the timing and duration of the drought spell. Drought stress affects many processes like leaf area development, the light use efficiency (reduction of photosynthesis when stomata close) and phenological development. These effects may be divided 
Table 3. Simulated results of a SUCROS potato model.

\begin{tabular}{|c|c|c|c|c|c|c|}
\hline \multirow{2}{*}{$\begin{array}{l}\text { Treatment } \\
\text { cultivar }\end{array}$} & \multicolumn{2}{|c|}{ Irrigated } & \multicolumn{2}{|c|}{ Early drought } & \multicolumn{2}{|c|}{ Late Drought } \\
\hline & Late & Early & Late & Early & Late & Early \\
\hline Total biomass $\left(\mathrm{t} \mathrm{ha}^{-1}\right)$ & 28.9 & 16.4 & 13.6 & 5.5 & 13.3 & 9.1 \\
\hline Tuber dry matter $\left(\mathrm{tha}^{-1}\right)$ & 22.4 & 13.2 & 10.2 & 3.7 & 7.4 & 6.0 \\
\hline Harvest index & 0.78 & 0.81 & 0.75 & 0.67 & 0.55 & 0.65 \\
\hline Highest $\mathrm{LAI}$ value & 7.4 & 3.8 & 4.8 & 2.5 & 7.4 & 3.8 \\
\hline Transpiration (mm) & 471 & 283 & 239 & 105 & 238 & 166 \\
\hline Transp. efficiency $\left(\mathrm{g} \mathrm{kg}^{-1}\right)$ & 6.33 & 5.99 & 5.92 & 5.52 & 5.95 & 5.85 \\
\hline
\end{tabular}

into short-term effects and long term effects. Short-term effects like stomatal closure or leaf rolling are reversible effects. The longer-term effects, like reduced leaf area development, phenological development are most important to consider here.

Quantitative understanding of the impact of drought on crop yield on basis of the effects on the different processes through crop models can be instrumental in targeting genotypes to different environments. A key characteristic in drought prone environments is the duration of the growing cycle of a variety. Depending on the probability of the occurrence of drought in different periods of the growing season, early or late varieties may have an advantage.

For potato in The Netherlands, Haverkort and Goudriaan (1994) found that yield losses due to drought were greatest with relatively early cultivars. This was mainly due to a reduction of the amount of intercepted radiation because of earlier senescence. The light-use efficiency was affected less than intercepted radiation. The tolerance of the late cultivars of drought resulted from its abundant formation of foliage associated with its lateness. Long-term effects of drought on crop growth in different potato varieties were simulated by Haverkort and Goudriaan (1994). They used 30 years average weather data and simulated potato growth assuming a sandy loam soil. When subjected to drought, leaf senescence was advanced by 30 days in the late cultivar and by about 20 days in the early cultivar which prevented recovery of the early cultivar in the second half of the growing season. The simulation results are shown in table 3. An early dry spell had a stronger impact on yield of an early cultivar, whereas a late dry spell affected the yield of the late cultivars more strongly. The late drought strongly reduced both tuber yield and harvest index as hardly any dry matter was partitioned to the tubers.

It may be concluded that the length of the growth cycle of a cultivar is the major factor determining tolerance of short transient or of late prolonged dry periods. Late cultivars initiate their tubers late and develop a lush canopy that 
is able to loose much leaf area before interception of solar radiation is affected. An early cultivar may be more suited to (Mediterranean) conditions in which drought gradually increases towards the end of the growing season. Increasing dry matter partitioning to the tubers leads to an escape from drought.

However, it is important to determine the trade-offs between traits that are useful in different production situations. Breeding for stress tolerance may sometimes inadvertently lead to a lower productivity under optimal conditions. For instance, cultivars with a low harvest index which produce abundant foliage are more tolerant of drought but have lower yields under optimum conditions than genotypes that produce less foliage (Haverkort and Schapendonk 1994).

A detailed simulation study for the performance of several crops (sorghum, maize and kenaf) in the semi arid tropics in Australia was presented by Muchow and Carberry (1993). They showed the great advantage of using models for the evaluation of crop types in extremely variable environments with respect to drought. They simulated yield probabilities for different crop types in different environments using many years of weather data. Their results indicated that the choice of crop type depends on the attitude to risk. For example, an earlier maturing variety improved yields in lower yielding years, and increased yield stability, but the variety performed less in higher yielding years. This analysis shows that well validated models can help fine tune variety design and selection based on long term yield assessments, whereas conventional agronomic evaluation would require enormous investments in time and money.

\section{Crop type designs and pest interactions}

Besides adaptation to the climatic conditions, resistance or tolerance to pests and diseases is important. The disease or pest multiplies less rapidly when the genotype is more resistant, whereas tolerance indicates the ability of the variety to grow while infected. Screening for specific pest resistance is relatively easy to conduct experimentally by infecting a wide range of genotypes in a plot. However, tolerance involves quantitative traits and may vary by location. Systems approaches may help to quantify physiological damage mechanisms and possibilities to compensate. Once the mechanism is known, traits can be identified for crop type designs.

An example is the compensation of early insect damage in rice. Systems approaches have helped to identify the role of the tillering capacity in compensating the effects of leaf removal by insects (Elings and Rubia, pers. comm.). The new rice crop type design, mentioned earlier in this paper, has a reduced tillering capacity to reduce the contribution of non productive tillers to increase yield potential. In view of designing crop ideosystems that meet objectives at the eco-regional level as stated in the introduction, it is essential to quantify the trade offs between the reduction of non productive tillers and 

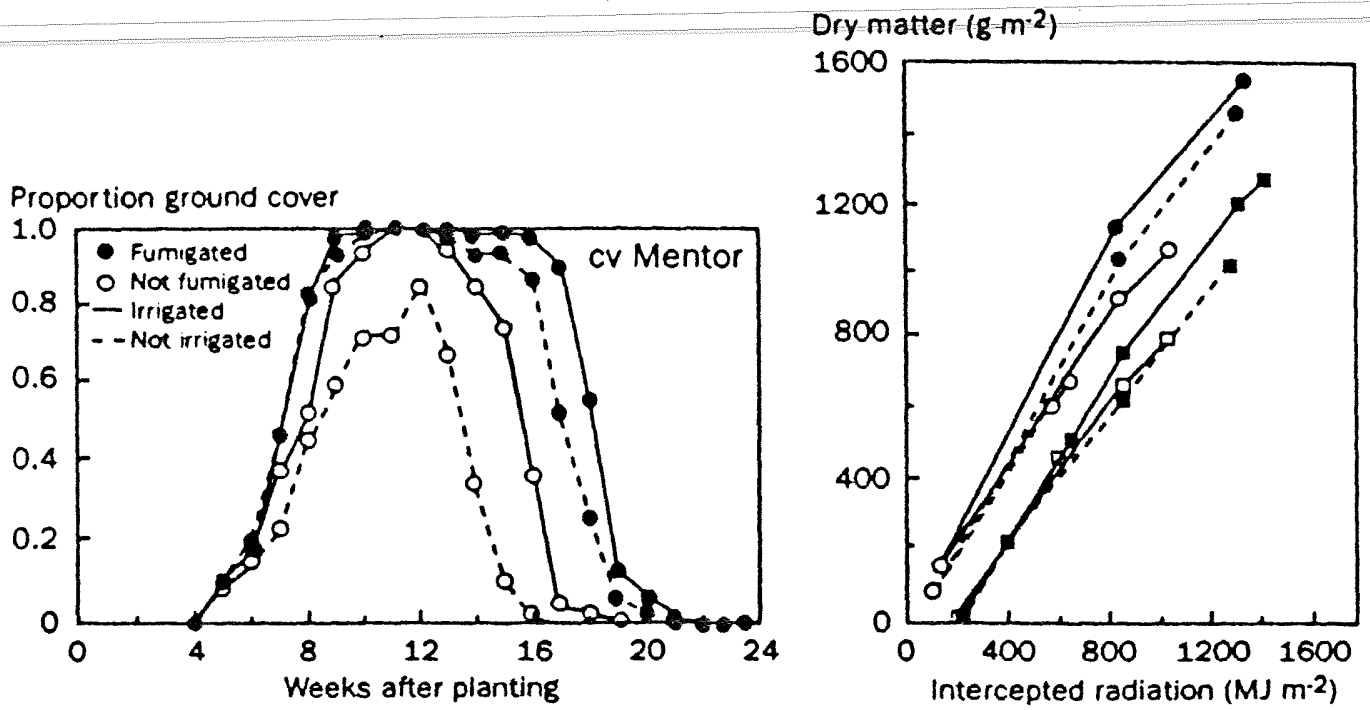

Fig. 4. Proportion of ground cover measured by infrared refiectance of potato crops subjected to drought and potato cyst nematodes. Irrigated, unirrigated, nematodes controlled (fumigated), nematodes not controlled (after Haverkort and Schapendonk 1994).

Table 4. Relative values of yield components in irrigated and unfumigated plots (mean data 1989 and 1990, values of irrigated and fumigated plots - 100). Parameters: (crop yield $Y$, $\left.\mathrm{g} \mathrm{m}^{-2}\right)$, the amount of photosynthetically active solar radiation intercepted $\left(R_{i}, \mathrm{~J} \mathrm{~m}^{-2}\right)$, the conversion efficiency into dry matter $\left(E, \mathrm{~g} \mathrm{~J}^{-1}\right)$, and the proportion of total dry matter in the harvested parts $\left(H_{i},-\right)$ and its dry matter content $\left(D_{m c}\right)$ (Haverkort et al. 1992).

\begin{tabular}{|c|c|c|c|c|c|c|}
\hline Cultivar & Yield & $-R_{\mathrm{i}}$ & $x$ & $\mathrm{E}$ & $\times \quad H_{i}$ & $/ D_{m c}$ \\
\hline Darwina & 48 & 61 & & 90 & 94 & 105 \\
\hline Desiree & 52 & $71^{\circ}$ & & 86 & 93 & 102 \\
\hline Elles & 73 & 86 & & 95 & 102 & 107 \\
\hline Mentor & 49 & 57 & & 92 & 100 & 101 \\
\hline
\end{tabular}

the compensation capacity to minimize pest damage after early leaf removal. Integrated experimental and modelling studies can help reveal these trade offs.

The effect of nematodes on potatoes was studied in detail by Haverkort et al. (1991, 1992). Figure 4 demonstrates the strong impact of nematodes and water stress on leaf area development (measured as infrared reflectance), resulting in a strong reduction of $R_{i}$. Infra-red reflectance and hence ground cover were reduced more strongly by nematodes than by drought. Table 4 shows the values of intercepted radiation, radiation-use efficiency, harvest index and dry matter content of the unfumigated plots relative to those of the fumigated controls. Apparently cyst nematodes and drought act similarly on the components of yield formation: yields are mainly reduced because crops 
intercept less solar radiation. Other factors reducing fresh tuber yields are lower light-use efficiencies whereas reduced harvest indices and increased dry matter contents also play a role. The cultivar least tolerant of nematode damage (Darwina) also was least tolerant of drought whereas cv. Elles was most tolerant of both stress factors.

These results indicate that varieties that quickly form a closed canopy and senesce slowly will be more tolerant to nematode and drought effects. This means that a larger specific leaf area (the formation of thinner leaves) a higher leaf water content (leading to larger leaves) and more and longer stems (allowing a better spread of the leaves over the soil surface with less overlap) are the major factors contributing to light interception with a given amount of dry matter partitioned to the crop tops.

Another example is the design of genotypes that have a higher competitive ability versus weeds. An ecophysiological simulation model for interplant competition was used to identify traits that determine the competitive ability of a crop. The most important traits were: rapid early leaf area - tiller - and height development, and more horizontally oriented leaves in early growth stages (vertical ones later on because of yield potential) (Kropff and Van Laar 1993). In experiments, rice varieties that differed in these traits were evaluated with respect to their competitive ability versus a standard purple colored variety. The variety with all required traits, Mahsuri, reduced the growth of the purple variety so much, that all purple rice plants had died before the final harvest (Kropff, unpublished results).

The studies mentioned show that quantitative ecophysiological understanding of the damage mechanisms and plant traits involved, can help designing crop ideotypes with a minimum pest damage which will help to reduce the use of pesticides to control pests. However, for insects and diseases, breeding for resistance will have to be continued, although it is known by now that the use of resistant varieties quickly leads to the development of new pest populations to which the crop lacks resistance. Approaches as the ones mentioned are complementary.

\section{Conclusions}

The examples given in this paper illustrate the potential of using systems approaches to increase our quantitative understanding of agricultural production systems and how such understanding can be used in the designing of crop ideosystems for target environments. This includes the variety and its management. A simple crop model based on intercepted radiation and the light use efficiency can be used as a first step in the analysis of experimental data, followed by more mechanistic analyses using detailed ecophysiological models. Once the mechanisms are identified, the models can be used to predict the performance of genotypes for different environments. How- 
ever, it is an essential requirement to identify the yield constraints in the target environments through yield gap analysis. Models can be helpful as a guideline.

With respect to breeding for increased potential yield, the approach used has to be suitable for the specific crops in their environments. In temperate environments, for most crops the duration has to be optimized in such a way that the crop uses the full growing season as determined by temperature. In potatoes the optimization of yield can be easily defined by using the model to identify the optimum duration to tuber initiation so that a leaf canopy is produced that can sustain a long tuber filling period. In rice the flowering date has to be optimized to match the season. This has been done by breeders, who developed varieties in temperate environments that require a low temperature sum to flowering. In the tropics the story is different, as more crops can be grown per year. Therefore the maximum yield with a relatively short duration has to be achieved for both rice and potatoes.

The paper clearly illustrates that a simple seed based technology as used in the in the past (improve the genotype, homogenize the environments through external inputs thereby minimizing $\mathrm{G} \times \mathrm{E}$ ) may not be the most suitable approach for sustainable eco-regional development. For that purpose, detailed $\mathrm{G} \times \mathrm{E}$ studies are needed in a wide range of environments, where experimentation and modelling are combined. Therefore, teamwork of breeders, physiologists, agronomists and modellers is an essential requirement in the process of designing ideosytems. Such an effort is underway in the Systems Analysis and Simulation in Rice Production project in which IRRI collaborates with National Agricultural Research Institutes in the region (Ten Berge et al. 1994) with the germplasm evaluation projects of IRRI and the NARS. The focus of this effort is to target crop types for specific environments based on understanding of the genotype $\times$ environment interactions.

\section{Acronyms}

$\begin{array}{ll}\text { CIP } & \text { Centro Internacional de la Papa (International Potato Center) } \\ \text { G } \times \text { E } & \text { Genotype by Environment } \\ \text { IRRI } & \text { Intemational Rice Research Institute } \\ \text { LAI } & \text { Leaf Area Index } \\ \text { LINTUL } & \text { Light INTerception and Utilization model } \\ \text { MACROS } & \text { Modules for an Annual CROp Simulator } \\ \text { NARS } & \text { National Agricultural Research System } \\ \text { SUCROS } & \text { Simple and Universal CROp growth Simulator }\end{array}$

\section{References}

Aggarwal P K, Kropff M J, Matthews R B, McLaren G (1995) Using simulation models to relate physiological traits to the performance of rice genotypes. Proceedings of the 
IRRI-ICRISAT-Univ. of Queensland meeting on genotype $\times$ environment interactions (in press).

Ten Berge H FM; Kropff M J, Wopereis M C S (Eds.) (1994) The SARP project Phase III (1992-1995) Overview, Goals, Plans. SARP Research Proceedings, IRRI, Los Banos, Philippines, and AB-DLO, Wageningen, The Netherlands.

Cassman K G, Kropff M J, Gaunt J, Peng S (1993) Nitrogen use efficiency of rice reconsidered: What are the key constraints? Plant and Soil 155/156:359-362.

Cassman K G, De Datta S K, Olk D C, Alcantara J M, Samson M I, Descalsota J P, Dizon M A (1994) Yield decline and the nitrogen economy of long-term experiments on continuous, irrigated rice systems in the tropics. Advances in Soil Science (in press).

Dingkuhn M, Penning de Vries F W T, De Datta S K, Van Laar H H (1991) Concept for a new plant type for direct seeded flooded tropical rice. Pages 17-39 in Direct seeded flooded rice in the tropics. Selected papers from the International Rice Research Conference, August 27-31, 1990, Seoul, Korea. IRRI, Los Banos, Philippines.

Donald C M (1962) In search of yield. J. Aust. Inst. Agric. Sci. 28:171-178.

Donald C M (1968) The breeding of crop ideotypes. Euphytica 17:385-403.

Evans L T (1990) Assimilation, allocation, explanation, extrapolation. Pages 77-87 in Rabbinge R, Goudriaan J, Van Keulen H, Penning de Vries F W T, Van Laar H H (Eds.) Theoretical Production Ecology: reflections and prospects. Simulation Monographs 34, Pudoc, Wageningen, The Netherlands.

Flinn J C, De Datta S K, Labadan, E (1982) An analysis of long-term rice yields in a wetland soil. Field Crops Research 5:201-216.

Haverkort A J (1990) Ecology of potato cropping systems in relation to latitude and altitude. Agricultural Systems 32:251-272.

Haverkort A J, Goudriaan J (1994) Perspectives of improved tolerance of drought in crops. Aspects of Applied Biology 38:79-92.

Haverkort A J, Harris P M (1987) A model for potato growth and yield under tropical highland conditions Agricultural an Forest Meteorology 39:271-282.

Haverkort A J, Schapendonk A H C M (1994) Crop reactions to environmental stress factors. Pages 339-346 in Struik P C, Vreedenberg W J, Renkema J A, Parlevliet J E (Eds.) Plant production on the threshold of a new century. Kluwer Academic Publishers, Dordrecht, The Netherlands.

Haverkort A J, Boerma M, Velema R, Van de Waart R, Van der Waart M (1992) The influence of drought and cyst nematodes on potato growth. 4. Effects on crop growth under field conditions of four cultivars differing in tolerance. Netherlands Journal of Plant Pathology 98:179-191.

Haverkort A J, Uenk D, Veroude H, Van de Waart M (1991) Relationships between ground cover, intercepted solar radiation, leaf area index and infrared reflectance of potato crops. Potato Research 34:113-121.

Hunt L A (1993) Designing improved plant types: a breeder's viewpoint. Pages 3-17 in Penning de Vries F W T, Teng P S, Metselaar K (Eds.) Systems Approaches for agricultural development. Kluwer Academic Publishers, The Netherlands.

IRRI (1989) IRRI towards 2000 and beyond. International Rice Research Institute, Los Banos, Philippines.

IRRI (1993) The IRRI rice almanac, The International Rice Research Institute, Los Banos, Philippines.

Kooman P L (1995) Yielding abilities of potato crops influenced by temperature and daylength. $\mathrm{PhD}$ thesis, Wageningen Agricultural University (in press).

Kooman P L, Haverkort A J (1995) Modeling development and growth of the potato crop influenced by daylength and temperature: LINTUL-POTATO. In Haverkort A J, MacKerron D K L (Eds.) Ecology and modeling of potato under conditions limiting growth. Kluwer Academic Publishers, Dordrecht, The Netherlands (in press).

Kropff M J, Van Laar H H (Eds.) (1993) Modeling crop-weed interactions. CAB, Wallingford and IRRI, Los Banos, Philippines. 
Kropff $M$ J, Cassman K G; Penning de Vries $F-W T$, Van Laar H H (1993a) Increasing the yield plateau and the impact of global climate change. J. Agric. Meteorol, 48:795-798.

Kropff M J, Cassman K G, Van Laar H H, Peng S (1993b) Nitrogen and yield potential of irrigated rice. Plant and Soil 155/156:391-394;

Kropff M J, Cassman K G, Van Laar H H (1994a) Quantitative understanding of the irrigated rice ecosystems and yield potential. Pages $97-114$ in Virmani S S (Ed.) Hybrid rice technology: new developments and future prospects. IRRI, Los Banos, Philippines.

Kropff M J, Cassman K G, Peng S, Matthews R B, Setter T L (1994b) Quantitative undestanding of yield potential. Pages 21-38 in Cassman K G (Ed.) Breaking the yield barrier. IRRI, Los Banos, Philippines.

Kropff M J, Van Laar H H, Matthews R B (Eds. (1994c) ORYZA 1: An ecophysiological model for irrigated rice production. SARP Research Proceedings, AB-DLO, Wageningen, The Netherlands, and IRRI, Los Banos, Philippines.

Kropff M J, Williams R L, Horie T, Angus J F, Singh U, Centeno H G, Cassman K G (1994d) Predicting the yield potential in different environments. In Yanco Symposium Research Proceedings (in press).

Muchow R C, Carberry P S (1993) Designing plant types for the semiarid tropics: agronomists' viewpoint. Pages 37-61 in Penning de Vries F W T, Teng P S, Metselaar K (Eds.) Systems approaches for agricultural development. Kluwer Academic Publishers, The Netherlands.

Peng S, Khush G S, Cassman K G (1994) Evolution of the new plant ideotype for increased yield potential. Pages 5-20 in Cassman K G (Ed.) Breaking the yield barrier. IRRI, Los Banos, Philippines.

Penning de Vries F W T (1991) Improving yields: designing and testing VHYVs. Pages 13-19 in Penning de Vries F W T, Kropff M J, Teng P S, Kirk G J D (Eds.) Systems Simulation at IRRI. IRRI Research Paper Series, November 1991, Number 151, Los Banos, Philippines.

Penning de Vries F W T (1993) Rice production and global climate change. Pages 175-189 in Penning de Vries F W T, Teng P S, Metselaar K (Eds.) Systems approaches for agricultural development. Kluwer Academic Publishers, The Netherlands.

Penning de Vries F W T, Jansen D M, Ten Berge H F M, Bakema A (1989) Simulation of ecophysiological processes of growth of several annual crops. Simulation Monographs 29. Pudoc, Wageningen, The Netherlands, and IRRI, Los Banos, Philippines.

Penning de Vries F W T. Teng P S, Metselaar K (Eds.) (1993) Systems Approaches for agricultural development. Kluwer Academic Publishers, Dordrecht/Boston/London, and IRRI, Los Banos, Philippines.

Spitters C J T, Van Keulen H, Van Kraalingen D W G (1989) A simple and universal crop growth simulator: SUCROS87. Pages 147-181 in Rabbinge R, Ward S A, Van Laar H H (Eds.) Simulation and systems management in crop protection. Simulation Monographs, Pudoc, Wageningen, The Netherlands. 